\title{
Transparent and Conductive Molybdenum-Doped ZnO Thin Films via Chemical Vapor Deposition
}

\author{
Donglei Zhao, Sanjayan Sathasivam, ${ }^{\circledR}$ Jianwei Li, and Claire J. Carmalt*i) \\ Materials Chemistry Centre, Department of Chemistry, University College London, 20 Gordon Street, London WC1H 0AJ, U.K. \\ Supporting Information
}

\begin{abstract}
Extrinsically doped $\mathrm{ZnO}$ is widely used as a transparent conducting electrode and has the potential to alleviate the demand on the expensive but ubiquitous $\mathrm{Sn}$-doped $\mathrm{In}_{2} \mathrm{O}_{3}$. Here, we report for the first time the synthesis and characterization of molybdenum-doped $\mathrm{ZnO}$ via a chemical vapor deposition route. Films were grown by using diethylzinc, molybdenum hexacarbonyl, toluene, and methanol. All films had visible light transmittance of $\sim 80 \%$ and electrical resistivity of $10^{-3} \Omega \cdot \mathrm{cm}$ with the lowest resistivity of $2.6 \times 10^{-3} \Omega \cdot \mathrm{cm}$ observed for the 0.57 at. \% Mo-doped film. X-ray photoelectron spectroscopy of the surface species and X-ray diffraction based calculations of the $\mathrm{ZnO}$ unit cell parameters suggest that Mo is present in the 4+ oxidation state, thus contributing two electrons for electrical conduction for every $\mathrm{Zn}^{2+}$ ion replaced in the lattice.
\end{abstract}

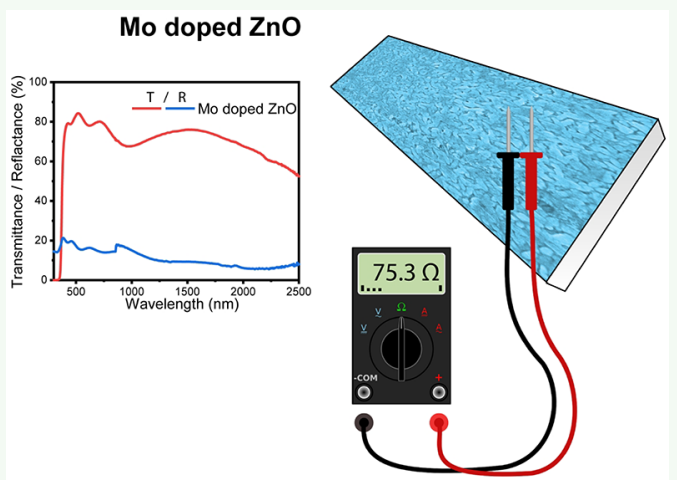

KEYWORDS: transparent conducting oxides, chemical vapor deposition, thin films, cation doping, zinc oxide

\section{INTRODUCTION}

Transparent conducting oxides (TCOs) are an important component in many widely used devices such as solar cells, flat-screen displays, and touchscreens. ${ }^{1-3}$ They are semiconductors that are transparent $(>80 \%)$ to the visible wavelengths of the electromagnetic spectrum because of an optical band gap of $\geq 3.1 \mathrm{eV}$ and have almost metal-like electrical resistivity $\left(\leq 10^{-3} \Omega \cdot \mathrm{cm}\right)$ due to extrinsic dopants. ${ }^{3-5}$ $\mathrm{Sn}$-doped $\mathrm{In}_{2} \mathrm{O}_{3}$ (ITO) is currently the most widely used TCO material achieving resistivities as low as $10^{-4}$ and $10^{-5} \Omega \cdot \mathrm{cm}$; however, because of the scarcity and high cost of indium, alternative materials are in high demand. ${ }^{6,7}$

$\mathrm{ZnO}$ is a nontoxic, earth abundant, and thus inexpensive semiconductor compared to $\operatorname{In}_{2} \mathrm{O}_{3}$. Furthermore, unlike ITO, $\mathrm{ZnO}$ is chemically stable under hydrogen plasma that is employed in the fabrication of microcrystalline Si based solar cells and thin film transistor-liquid crystal displays (TFTLCDs). ${ }^{8,9} \mathrm{ZnO}$ is highly suitable as a TCO due to its optical band gap of $3.37 \mathrm{eV}$ and intrinsic n-type conductivity that is thought to originate from adventitious hydrogen. ${ }^{10,11}$ However, the resistivity of nominally undoped $\mathrm{ZnO}$ is often too high for application in electronic devices. To reduce the resistivity to $10^{-3} \Omega \cdot \mathrm{cm}$ or below, extrinsic donor dopants are necessary. $\mathrm{Al}^{3+}$ is widely used, as it is a shallow donor dopant in $\mathrm{ZnO}$ that contributes to one electron for conduction for every $\mathrm{Zn}^{2+}$ substituted. However, because of the small ionic radius of $\mathrm{Al}^{3+}(0.39 \AA)$, ZnO:Al can suffer from poor stability. ${ }^{9,12}$ Another donor dopant that is also often used is $\mathrm{Ga}^{3+}$ which has a larger ionic radius of $0.47 \AA$ and shows better stability while donating one electron for conductivity. ${ }^{9,12}$ Recently, a strategy to further enhance the conductivity of $\mathrm{ZnO}$ by using even higher valence donor dopants (e.g., $\mathrm{W}, \mathrm{Nb}$, and $\mathrm{Mo}$ ) that can contribute more than one electron for conduction have been employed. ${ }^{8,13,14}$

Mo is stable in the 4+ or $6+$ oxidation states and thus when substitutionally doped on $\mathrm{Zn}$ sites can contribute two or four electrons, respectively, into the conduction band of $\mathrm{ZnO}$ to enhance the electrical conductivity. Previous studies for Modoped $\mathrm{ZnO}$ have shown promising resistivities in the $10^{-3}$ and $10^{-4} \Omega \cdot \mathrm{cm}$ range. ${ }^{8,15-17}$ However, these films have, in most cases, been grown by ultrahigh-vacuum physical vapor deposition (PVD) techniques. ${ }^{8,15,17}$ To date, no Mo-doped $\mathrm{ZnO}$ films have been grown via chemical vapor deposition (CVD).

Aerosol-assisted chemical vapor deposition (AACVD) is a specialized form of CVD used to prepare thin films. AACVD uses soluble precursors instead of vaporizing volatile precursors used in the traditional atmospheric pressure (AP)CVD, which could offer a larger range of precursors to be chosen to avoid some of hazards, including corrosivity, pyrophoricity, flammability, explosivity, and environmental toxicity. ${ }^{18,19}$ Compared to other synthetic technologies, there are also some other benefits of AACVD, such as easily controlled morphology, stoichiometry, and film thickness and a relatively simple process that operates at ambient pressure, resulting in low cost. $^{18-24}$ Hence, AACVD is a prospective method to synthesize TCO thin films. Moreover, AACVD has been

Received: October 3, 2019

Accepted: December 18, 2019

Published: December 18, 2019 
a)

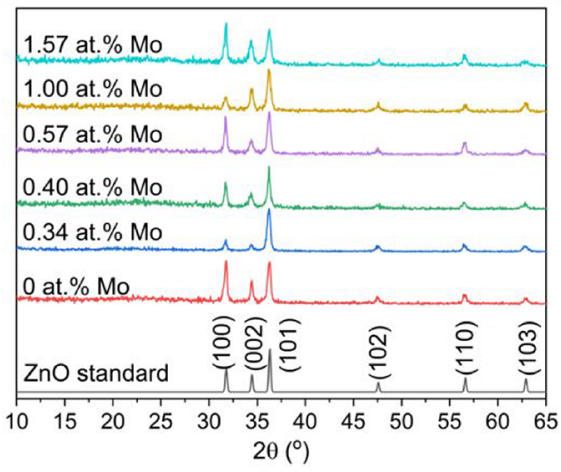

b)

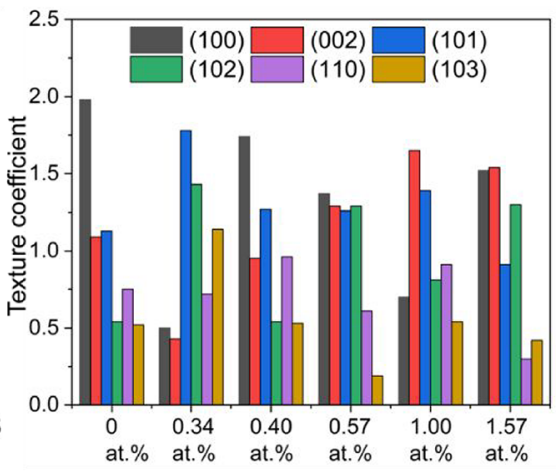

Figure 1. (a) XRD patterns showing the standard, undoped, and Mo-doped $\mathrm{ZnO}$ films prepared at $450{ }^{\circ} \mathrm{C}$ to be in the wurzite phase of $\mathrm{ZnO}$. No secondary phases are visible. (b) Results of the texture coefficient calculation. A TC value of above 1 indicates preference in that direction.

used to fabricate many thin films with excellent functional properties. $^{22,23,25}$

In this paper, the growth of Mo-doped $\mathrm{ZnO}$ thin films on glass substrates via aerosol-assisted chemical vapor deposition (AACVD), a specialized form of CVD that is easily scalable and cost-effective, operating at ambient pressure has been investigated. $^{18}$

\section{EXPERIMENTAL SECTION}

Film Synthesis. Caution! Diethylzinc is a pyrophoric substance that ignites spontaneously in air and therefore must be handled under an inert atmosphere.

Depositions were performed under $\mathrm{N}_{2}$ (BOC Ltd., 99.99\% purity) flow. Diethylzinc $\left(\mathrm{ZnEt}_{2}, 15\right.$ wt \%) in toluene (99\%), molybdenum hexacarbonyl ([Mo(CO) 6$], 99 \%)$, and methanol (99\%) were purchased from Sigma. The methanol was freshly dried over magnesium and stored over sieves prior to use while $\mathrm{ZnEt}_{2}$ and $\left[\mathrm{Mo}(\mathrm{CO})_{6}\right]$ were used as received. Toluene was purchased from Alfa Aesar and stored under alumina columns and dried with Anhydrous Engineering equipment. Glass substrates were cleaned with detergent, water, and isopropanol and then dried in a $70{ }^{\circ} \mathrm{C}$ oven.

$\mathrm{ZnEt}_{2}(0.5 \mathrm{~g}, 4.05 \mathrm{mmol})$ in toluene $(20 \mathrm{~mL})$ was placed in a glass bubbler. In a separate bubbler, $\left[\mathrm{Mo}(\mathrm{CO})_{6}\right](0.5,1,2,3$, and $4 \mathrm{~mol} \%$ relative to $\mathrm{Zn})$ was dissolved in methanol $(20 \mathrm{~mL})$. Both bubblers were connected to the CVD reactor via a Y-piece. The solutions were atomized by using a piezoelectric device (Johnson Matthey liquifog). The aerosol mists were delivered to the AACVD reaction chamber via a $\mathrm{Y}$ piece and a water-cooled baffle and passed over the heated substrate (float glass with a $\mathrm{SiO}_{2}$ barrier layer) by using $\mathrm{N}_{2}$ carrier gas at $0.6 \mathrm{~L} \mathrm{~min}{ }^{-1} \times 2 .{ }^{26}$ Depositions were performed at $450{ }^{\circ} \mathrm{C}$ and lasted until the precursor solution was fully used. After the deposition the substrates were cooled under a flow of $\mathrm{N}_{2}$. The glass substrate was allowed to cool with the graphite block to $<50{ }^{\circ} \mathrm{C}$ before it was removed. Coated substrates were handled and stored in air.

Film Characterization. X-ray diffraction (XRD) was performed by using a modified Bruker-Axs D8 diffractometer with parallel beam optics and a PSD LynxEye silicon strip detector. A monochromated $\mathrm{Cu} \mathrm{K} \alpha$ source operated at $40 \mathrm{kV}$ with $30 \mathrm{~mA}$ emission current was used. The incident beam angle was set at $0.5^{\circ}$, and the $2 \theta$ range of $10^{\circ}-65^{\circ}$ was measured with a step size of $0.05^{\circ}$ at 1 s/step. A JEOL JSM-6301F field emission SEM at an accelerating voltage of $5 \mathrm{keV}$ was used for scanning electron microscopy (SEM) measurements (samples were coated with gold to avoid charging). Optical measurements were performed using a PerkinElmer Fourier transform Lambda 950 spectrometer over a wavelength range of 300-2500 nm. X-ray photoelectron spectroscopy (XPS) was performed by using a Thermo Scientific K $\alpha$ photoelectron spectrometer using monochromatic $\mathrm{Al} \mathrm{K} \alpha$ radiation. Higher resolution scans were recorded for the principal peaks of $\mathrm{Mo}(3 \mathrm{~d}), \mathrm{Zn}(2 \mathrm{p}), \mathrm{O}(1 \mathrm{~s})$, and $\mathrm{C}(1 \mathrm{~s})$ at a pass energy of $50 \mathrm{eV}$. The peaks were modeled by using CasaXPS software with binding energies adjusted to adventitious carbon $(284.5 \mathrm{eV})$ for charge correction. Hall effect measurements were performed using the van Der Pauw method to determine the resistivity $(\rho)$, free carrier concentration $(n)$, and mobility $(\mu)$.

\section{RESULTS AND DISCUSSION}

Nominally undoped and Mo-doped $\mathrm{ZnO}$ films were grown on glass substrates from the two-pot AACVD reaction of $\mathrm{ZnEt}_{2}$ in toluene and $\left[\mathrm{Mo}(\mathrm{CO})_{6}\right]$ in methanol at $450{ }^{\circ} \mathrm{C}$ under $\mathrm{N}_{2}$ flow (see the Supporting Information). All films were well adhered to the substrate, which passed the Scotch tape test. ${ }^{27}$ The bulk Mo concentration in the films was determined via energy dispersive X-ray spectroscopy (EDS) to be 0, 0.34, 0.40, 0.57, 1.00 , and 1.57 at. $\%$ from the $0.5,1,2,3$, and $4 \mathrm{~mol} \%$ relative to $\mathrm{Zn}$ of $\mathrm{Mo}(\mathrm{CO})_{6}$ in the AACVD precursor solution (see the Supporting Information).

Figure 1a describes the X-ray diffraction patterns for the undoped and $\mathrm{Mo}$ doped $\mathrm{ZnO}$ thin films. Bragg reflections were seen at $31.8^{\circ}, 34.4^{\circ}, 36.3^{\circ}, 47.5^{\circ}, 56.6^{\circ}$, and $63.0^{\circ}$, which can match the standard data of $\mathrm{ZnO}$ pattern and represent the (100), (002), (101), (102), (110), and (103) planes of the expected wurtzite phase of $\mathrm{ZnO}{ }^{28}$ No secondary oxide phases for zinc and/or molybdenum were visible. Applying the Scherrer equation to the XRD data showed that the undoped $\mathrm{ZnO}$ film had an estimated crystallite size of ca. $30 \mathrm{~nm}$ while the doped samples were all roughly $20 \mathrm{~nm}$ (see the Supporting Information). It is important to note that the Scherrer equation has a large associated error, and therefore the values obtained only provide an indication of trends. ${ }^{29}$

Typical of AACVD grown thin films, compared to the standard pattern, all the films studied here show degrees of preferred orientation in various crystallographic directions. The preferred orientation was quantified by determining the texture coefficient (TC) for each plane with the results shown in Figure $1 \mathrm{~b}$, where TC values above one indicate a preference for that plane and a TC value below one is a lack of preference. The undoped $\mathrm{ZnO}$ film prefers to grow in the (100) plane and shows a lack of growth of the (102), (110), and (103) planes. Again, this is likely a result of substrate influence. ${ }^{30}$ With Mo doping, in most cases, the (100) and (101) planes are preferred, with the (002) plane also preferred but only at the higher doping levels of $0.57,1.00$, and 1.57 at. \%. This is atypical of previous reports of Mo-doped $\mathrm{ZnO}$ thin films and cation ( $\mathrm{Al}, \mathrm{Ga}, \mathrm{W}, \mathrm{Sc}$, and $\mathrm{Mg}$ )-doped $\mathrm{ZnO}$ in general, which all show only a strong preference for the (002) plane. $^{15-17,19,31-35}$ This is expected as the (002) plane has 
the lowest surface energy in the $\mathrm{ZnO}$ crystal. The impact of the preferred orientation on the morphology of the films as determined via scanning electron microscopy (SEM) images can be found in Figure 2. The nominally undoped film

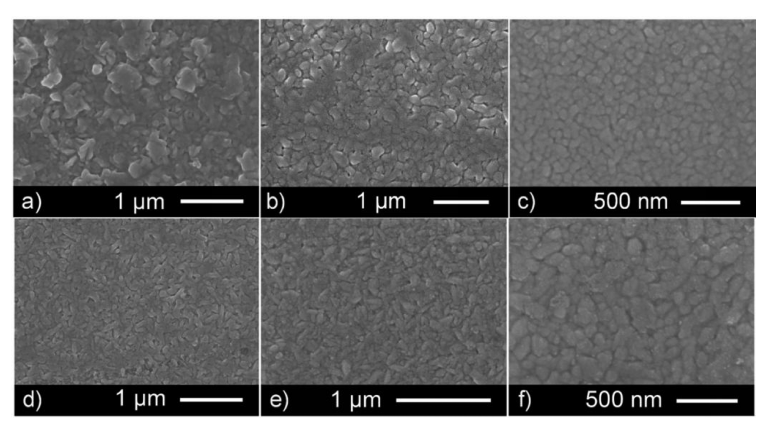

Figure 2. SEM images for the morphology of the (a) undoped and (b) 0.34, (c) 0.40, (d) 0.57, (e) 1.00, and (f) 1.57 at. \% Mo-doped $\mathrm{ZnO}$ films prepared through AACVD.

shows a morphology consisting of platelet-like features of varying sizes randomly orientated. The morphology of $\mathrm{ZnO}$ films is dependent on a range of factors including substrate, substrate temperature, carrier gas, precursor, and oxidant source. $\mathrm{ZnO}$ films grown on glass from $\mathrm{ZnEt}_{2}$ by using AACVD often have platelet-like features such as the ones seen here. Upon the introduction of $\mathrm{Mo}$, the $\mathrm{ZnO}$ films appear to become flatter with the morphology composed of globular grains of various dimensions that are parallel to the substrate. This is supported by the XRD results where preferred orientation was observed in various crystallographic directions for the $\mathrm{ZnO}$ :Mo films. This indicates that crystal growth was taking place evenly as opposed to in one particular plane, such as the (002) which often grows perpendicular to the substrate leading to a more textured morphology.

The X-ray photoelectron spectroscopy (XPS) results for the deposited thin films can be seen in Figure 3. As expected, the oxidation state of $\mathrm{Zn}$ in all cases is $2+$, with a binding energy of $1022.1 \mathrm{eV}$ observed for $2 \mathrm{p}_{3 / 2}$, which corresponds well with literature results for $\mathrm{ZnO}$ (Figure 3a). ${ }^{36}$ For the Mo-doped samples the $\mathrm{Zn}_{3 / 2}$ peak position generally shifts to slightly lower values between 1021.5 and $1021.8 \mathrm{eV}$ (Figure 3a). Figure $3 \mathrm{~b}$ displays the high-resolution scans in the Mo $3 \mathrm{~d}$ region which were performed for all films. For dopant concentrations between 0.34 and 0.57 at. \%, only a small bump with a low signal-to-noise ratio was observed, and thus peak fitting to determine oxidation state was not practical (Figure $3 \mathrm{~b}$ ). For the 1.00 and 1.57 at. \% Mo films, peak fitting of the asymmetric Mo 3d peaks was performed using a pair of doublets. The primary $3 d_{5 / 2}$ peak for both films was centered at $232.2 \mathrm{eV}$, matching $\mathrm{Mo}^{6+}$ with the secondary $3 \mathrm{~d}_{5 / 2}$ peak situated at $230.4 \mathrm{eV}$ and corresponding to $\mathrm{Mo}^{4+}{ }^{37}$

The $\mathrm{Mo}^{6+}$ observed on the surface of both the 1.00 and 1.57 at. \% doped films is likely a result of surface oxidation and has been previously reported for Mo-doped metal oxides. ${ }^{38}$ Without bulk analytical techniques such as hard XPS (HAXPES), it is difficult to confirm the oxidation state of the Mo within the bulk; however, the detection of $\mathrm{Mo}^{4+}$ on the surface despite surface oxidation and the ionic radius of $\mathrm{Zn}^{2+}$ $(0.6 \AA)$ being more closely matched to that of $\mathrm{Mo}^{4+}(0.65 \AA)$ than that of $\mathrm{Mo}^{6+}(0.41 \AA)$ suggests that $\mathrm{Mo}^{4+}$ is likely the principal form in the bulk. This is confirmed by the unit cell parameters calculations that showed upon doping an expansion of the $\mathrm{ZnO}$ lattice was observed as opposed to a contraction.

The unit cell parameters of undoped and doped films were determined by the modeling of the XRD patterns using JADE software (Table 1). The parameters $a$ and $c$ and the volume for the nominally undoped $\mathrm{ZnO}$ were calculated to be $3.2522(2)$ $\AA$, 5.2103(3) $\AA$, and 55.108(6) $\AA^{3}$, respectively. These values are slightly larger than the standard values $(3.243 \AA$, $5.195 \AA$, and $54.636 \AA^{3}$ ) for wurtzite $\mathrm{ZnO}$, primarily due to substrateinduced strain on the CVD grown thin films. ${ }^{30,39}$ Upon doping with $\mathrm{Mo}$, the unit cell expands linearly (intercept $=55.108(4)$ $\AA^{3}$, slope $=0.12(3)$, and $\left.R^{2}=0.85\right)$ with dopant concentration (see the Supporting Information). This also suggests that substitutional doping is indeed taking place with Mo replacing $\mathrm{Zn}$ as opposed to only $\mathrm{MoO}_{x}$ phase formation. a)

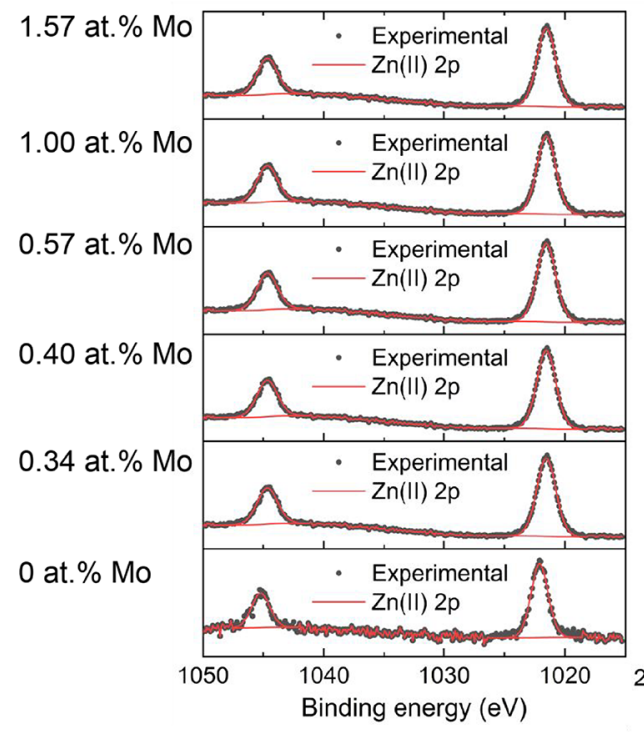

b)

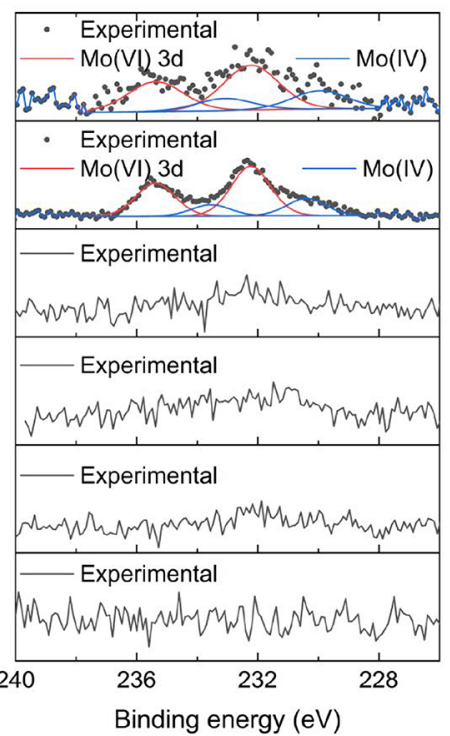

Figure 3. Core level XPS analysis showing the oxidation states of the (a) $\mathrm{Zn}$ and (b) Mo on the surface of the undoped and Mo-doped $\mathrm{ZnO}$ films. 
Table 1. Unit Cell Parameters for the Undoped and MoDoped ZnO Films Grown via AACVD

\begin{tabular}{cccc} 
& \multicolumn{3}{c}{ unit cell parameters } \\
\cline { 2 - 4 } Mo concn (at. \%) & $a(\AA)$ & $c(\AA)$ & $\operatorname{vol}\left(\AA^{3}\right)$ \\
0 & $3.2522(2)$ & $5.2103(3)$ & $55.108(6)$ \\
0.34 & $3.252(2)$ & $5.21(3)$ & $55.10(6)$ \\
0.40 & $3.254(2)$ & $5.212(6)$ & $55.19(8)$ \\
0.57 & $3.256(2)$ & $5.211(5)$ & $55.25(7)$ \\
1.00 & $3.257(2)$ & $5.205(2)$ & $55.22(5)$ \\
1.57 & $3.257(3)$ & $5.212(6)$ & $55.29(10)$ \\
\hline
\end{tabular}

Figure 4 shows the bulk concentration, carrier mobility, and resistivity of the $\mathrm{ZnO}$ and Mo-doped $\mathrm{ZnO}$ films from the Hall

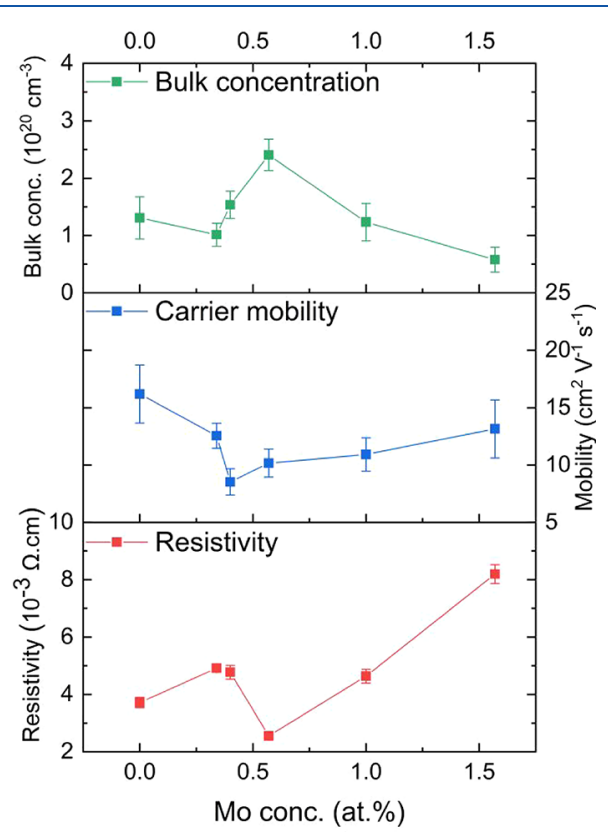

Figure 4. Electrical properties of the undoped and Mo-doped $\mathrm{ZnO}$ films derived from Hall measurements displaying the trend in bulk concentration, carrier mobility, and resistivity.

measurements. The nominally undoped sample has a bulk concentration of $1.31 \times 10^{20} \mathrm{~cm}^{-3}$ and a mobility of $16.19 \mathrm{~cm}^{2}$ $\mathrm{V}^{-1} \mathrm{~s}^{-1}$, leading to a resistivity of $3.7 \times 10^{-3} \Omega \cdot \mathrm{cm}$. The bulk concentration is high for a pure $\mathrm{ZnO}$ sample but not atypical of $\mathrm{ZnO}$ films grown by using $\mathrm{ZnEt}_{2}{ }^{26}$ Though not fully understood, the high intrinsic conductivity is attributed to adventitious hydrogen. ${ }^{10,11,26}$ Upon incorporation of Mo into the lattice, there is a slight drop in the bulk concentration to $1.01 \times 10^{20} \mathrm{~cm}^{-3}$ (presumably due to possible selfcompensating mechanisms, e.g., the formation of $\mathrm{Zn}$ vacancies), ${ }^{9}$ a drop in the carrier mobility, and thus an increase in the resistivity to $4.9 \times 10^{-3} \Omega \cdot \mathrm{cm}$. The lowest resistivity of $2.6 \times 10^{-3} \Omega \cdot \mathrm{cm}$ was measured for the 0.57 at. \% Mo concentration arising primarily from a high bulk concentration of $2.4 \times 10^{20} \mathrm{~cm}^{-3}$ as two donor electrons are released for conduction for every $\mathrm{Zn}^{2+}$ substituted with $\mathrm{Mo}^{4+}$. At higher concentrations of Mo (1.00 and 1.57 at. \%) the bulk concentration decreases $\left(1.2 \times 10^{20}\right.$ and $0.6 \times 10^{20} \mathrm{~cm}^{-3}$, respectively) due to self-compensation, e.g., the formation of acceptor point defects such as $\mathrm{Zn}$ vacancies that counter the effect of the donor $\mathrm{Mo}^{4+}$ dopant. $^{40}$ Another possible factor for the decrease in carrier concentration and conductivity is that possible limits of Mo solubility in $\mathrm{ZnO}$ have been reached, giving rise to the formation of electrically inactive $\mathrm{MoO}_{x}$ secondary phases. Previous literature examples of Mo-doped $\mathrm{ZnO}$ have estimated the solubility limit of $\mathrm{Mo}$ in $\mathrm{ZnO}$ to be at ca. 1 at. $\%{ }^{41}$ As a result of these reasons, an increase in resistivity to 4.6 and $8.2 \times 10^{-3} \Omega \cdot \mathrm{cm}$ was observed. The carrier mobility of the $\mathrm{ZnO}: \mathrm{Mo}$ films with lowest resistivity (0.57 at. \%) is $10.2 \mathrm{~cm}^{2} \mathrm{~V}^{-1} \mathrm{~s}^{-1}$, which is above the highest carrier mobility data of Sc-doped $\mathrm{ZnO}\left(7.5 \mathrm{~cm} \mathrm{~cm}^{2} \mathrm{~V}^{-1} \mathrm{~s}^{-1}\right){ }^{19}$ Al-doped $\mathrm{ZnO}\left(9.0 \mathrm{~cm} \mathrm{~cm}^{2} \mathrm{~V}^{-1} \mathrm{~s}^{-1}\right){ }^{42}$ Ga-doped $\mathrm{ZnO}(10.1$ $\left.\mathrm{cm} \mathrm{cm}^{2} \mathrm{~V}^{-1} \mathrm{~s}^{-1}\right),{ }^{42}$ and In-doped $\mathrm{ZnO}\left(5.1 \mathrm{~cm} \mathrm{~cm}^{2} \mathrm{~V}^{-1} \mathrm{~s}^{-1}\right)^{42}$ synthesized through AACVD.

The electrical properties reported in the literature for $\mathrm{ZnO}$ :Mo films grown via PVD techniques such as reactive magnetron sputtering and radio-frequency (RF) magnetron sputtering are lower compared to the AACVD results here. Xiu et al. report a resistivity that is quite low at $9.2 \times 10^{-4} \Omega \cdot \mathrm{cm}$ for RF magnetron grown films on glass substrates. ${ }^{17}$ Another low resistivity at $7.9 \times 10^{-4} \Omega \cdot \mathrm{cm}$ was achieved by $\mathrm{Wu}$ et al. for reactive magnetron sputtered films. ${ }^{8}$ Such low resistivities were obtained due to high carrier mobilities of 30.0 and $27.3 \mathrm{~V}^{-1}$ $\mathrm{s}^{-1}$, which are nearly three times larger than what was seen for the films in this study. However, the synthetic route involving AACVD is advantageous compared to PVD routes in that it operates at ambient pressure and is highly scalable by using inexpensive precursors, especially in the case of $\left[\mathrm{Mo}(\mathrm{CO})_{6}\right]^{21}$ Furthermore, the resistivity of $2.6 \times 10^{-3} \Omega \cdot \mathrm{cm}$ for the 0.57 at. $\%$ Mo doped $\mathrm{ZnO}$ film in this study is the lowest resistivity recorded for a $\mathrm{ZnO}$ :Mo film synthesized through a CVD route. In addition, compared to some other doped $\mathrm{ZnO}$ films, which have the same synthetic route (AACVD) as $\mathrm{ZnO}$ :Mo film in this study, our $\mathrm{ZnO}$ :Mo film shows a relatively low resistivity of $2.6 \times 10^{-3} \Omega \cdot \mathrm{cm}$, while the lowest resistivity of Al-doped $\mathrm{ZnO}$, Ga-doped $\mathrm{ZnO}$, and In-doped $\mathrm{ZnO}$ were $0.5 \times 10^{-2}, 1.3$ $\times 10^{-2}$, and $1.7 \times 10^{-2} \Omega \cdot \mathrm{cm}$, respectively. ${ }^{41,42}$

Figure 5a shows the ultraviolet-visible (UV-vis) spectra for the films on glass substrates between 300 and $2500 \mathrm{~nm}$. The average transmittance of visible light $(400-700 \mathrm{~nm})$ for all films is ca. $80 \%$ and is comparable to the PVD and spray pyrolysis grown films reported in the literature. ${ }^{8,16,17}$ In general the transmittance in the near-infrared region decreases with increasing bulk concentration. The reflectance of the films is on average $\geq 20 \%$ across all wavelengths and again comparable to literature findings. ${ }^{8,16,17}$ Both the nominally undoped and the doped films showed a band gap between 3.3 and $3.4 \mathrm{eV}$, matching closely to the expected value of $3.37 \mathrm{eV}$ (Figure 5b).

\section{CONCLUSION}

Polycrystalline $\mathrm{ZnO}$ and Mo-doped $\mathrm{ZnO}$ thin films were grown on glass substrates by using AACVD. XRD analysis showed all films to have no visible phase separation, with the unit cell parameters calculated to show an expansion in the $\mathrm{ZnO}$ lattice with Mo incorporation. This suggests that $\mathrm{Mo}^{4+}$, with the larger ionic radius compared to $\mathrm{Zn}^{2+}$, was the primary dopant instead of $\mathrm{Mo}^{6+}$. XPS analysis of the surface showed both $\mathrm{Mo}^{4+}$ and $\mathrm{Mo}^{6+}$ (possibly due to surface oxidation) were present. Hall effect measurements showed all films had low resistivity with the 0.57 at. \% $\mathrm{ZnO}: \mathrm{Mo}$ film having the minimum resistivity of $2.6 \times 10^{-3} \Omega \cdot \mathrm{cm}$ because of a relatively high carrier concentration of $2.4 \times 10^{20} \mathrm{~cm}^{-3}$. This is the lowest resistivity reported for a $\mathrm{ZnO}: \mathrm{Mo}$ film on glass deposited from a chemical deposition route and the only reported instance of electrically conductive $\mathrm{ZnO}$ :Mo having 

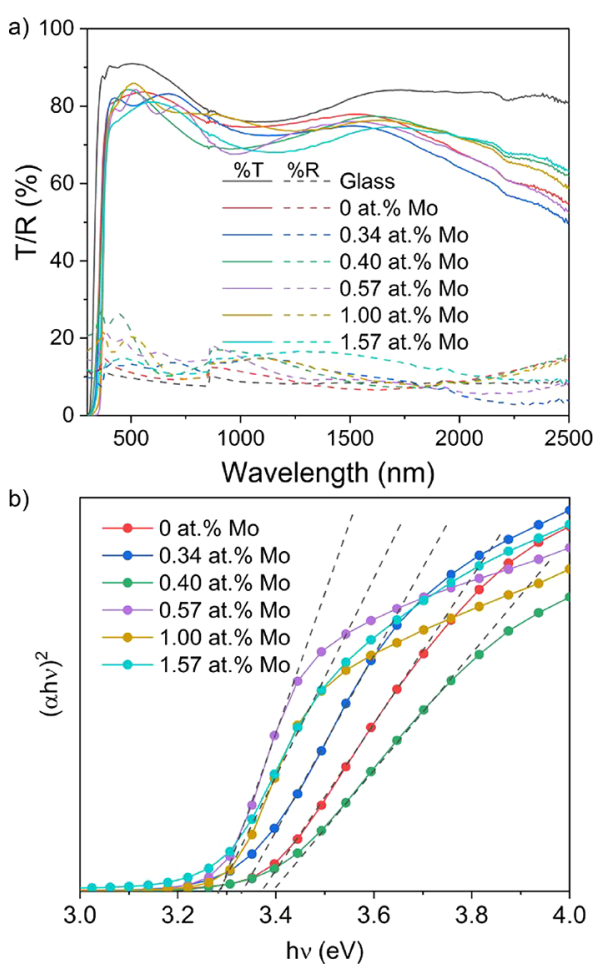

Figure 5. Optical data for the undoped and Mo-doped $\mathrm{ZnO}$ films on glass substrates showing the (a) UV/vis spectra and (b) Tauc plots.

been deposited via AACVD, which is considered as a prospective synthetic technology.

\section{ASSOCIATED CONTENT}

\section{S Supporting Information}

The Supporting Information is available free of charge at https://pubs.acs.org/doi/10.1021/acsaelm.9b00647.

AACVD reaction pathway scheme, crystallite size via the Scherrer method, unit cell volume and dopant concentration correlation (PDF)

\section{AUTHOR INFORMATION}

\section{Corresponding Author}

* E-mail c.j.carmalt@ucl.ac.uk.

ORCID $\odot$

Sanjayan Sathasivam: 0000-0002-5206-9558

Claire J. Carmalt: 0000-0003-1788-6971

\section{Notes}

The authors declare no competing financial interest.

\section{ACKNOWLEDGMENTS}

The authors thank Dr. Steve Firth for useful discussions and for assistance with the SEM. Dr. Tom Gregory is thanked for assistance with EDS analysis and Martin Vickers for XRD. Dr. Chris Blackman is also thanked for very helpful discussions. Donglei Zhao is thankful for the funding from China Scholarship Council (CSC). EPSRC is thanked for funding $\mathrm{EP} / \mathrm{N01572X/1} \mathrm{(S.S.)} \mathrm{and} \mathrm{EP/L017709/1} \mathrm{(C.J.C.).}$

\section{REFERENCES}

(1) Minami, T. Transparent Conducting Oxide Semiconductors for Transparent Electrodes. Semicond. Sci. Technol. 2005, 20 (4), S35S44.
(2) Godinho, K. G.; Carey, J. J.; Morgan, B. J.; Scanlon, D. O.; Watson, G. W. Understanding Conductivity in $\mathrm{SrCu} 2 \mathrm{O}$ 2: Stability, Geometry and Electronic Structure of Intrinsic Defects from First Principles. J. Mater. Chem. 2010, 20 (6), 1086-1096.

(3) Dixon, S. C.; Scanlon, D. O.; Carmalt, C. J.; Parkin, I. P. N-Type Doped Transparent Conducting Binary Oxides: An Overview. J. Mater. Chem. C 2016, 4, 6946-6961.

(4) Fortunato, E.; Ginley, D.; Hosono, H.; Paine, D. C. T Ransparent Conducting Oxides for Photovoltaics. MRS Bull. 2007, 32 (3), 242-247.

(5) Jiamprasertboon, A.; Dixon, S. C.; Sathasivam, S.; Powell, M. J.; Lu, Y.; Siritanon, T.; Carmalt, C. J. Low-Cost One-Step Fabrication of Highly Conductive $\mathrm{ZnO}$ : $\mathrm{Cl}$ Transparent Thin Films with Tuneable Photocatalytic Properties via Aerosol-Assisted Chemical Vapour Deposition. ACS Appl. Electron. Mater. 2019, 1, 1408-1417.

(6) Lewis, B. G.; Paine, D. C. Applications and Processing of Transparent Conducting Oxides. MRS Bull. 2000, 25, 22-27.

(7) Minami, T. Substitution of Transparent Conducting Oxide Thin Films for Indium Tin Oxide Transparent Electrode Applications. Thin Solid Films 2008, 516 (7), 1314-1321.

(8) Wu, C.; Shen, J.; Ma, J.; Wang, S.; Zhang, Z.; Yang, X. Electrical and Optical Properties of Molybdenum-Doped $\mathrm{ZnO}$ Transparent Conductive Thin Films Prepared by Dc Reactive Magnetron Sputtering. Semicond. Sci. Technol. 2009, 24 (12), 125012.

(9) Ellmer, K.; Bikowski, A. Intrinsic and Extrinsic Doping of $\mathrm{ZnO}$ and ZnO Alloys. J. Phys. D: Appl. Phys. 2016, 49 (41), 413002.

(10) McCluskey, M. D.; Jokela, S. J. Defects in Zno. J. Appl. Phys. 2009, 106 (7), 071101.

(11) Janotti, A.; Van de Walle, C. G. Native Point Defects in $\mathrm{ZnO}$ Phys. Rev. B: Condens. Matter Mater. Phys. 2007, 76 (16), 165202.

(12) Sanger, A.; Kang, S. B.; Jeong, M. H.; Kim, C. U.; Baik, J. M.; Choi, K. J. All-Transparent NO2 Gas Sensor Based on Free-Standing Al Doped ZnO Nanofibers. ACS Appl. Electron. Mater. 2019, 1, 12611268.

(13) Can, M. M.; Firat, T.; Shah, S. I. Magnetoelectrical Properties of W Doped ZnO Thin Films. J. Magn. Magn. Mater. 2012, 324 (23), 4054-4060.

(14) Shao, J.; Dong, W.; Li, D.; Tao, R.; Deng, Z.; Wang, T.; Meng, G.; Zhou, S.; Fang, X. Metal-Semiconductor Transition in Nb-Doped $\mathrm{ZnO}$ Thin Films Prepared by Pulsed Laser Deposition. Thin Solid Films 2010, 518 (18), 5288-5291.

(15) Yu, C.; Yang, K.; Shu, Q.; Yu, J. C.; Cao, F.; Li, X.; Zhou, X. Preparation, Characterization and Photocatalytic Performance of MoDoped ZnO Photocatalysts. Sci. China: Chem. 2012, 55 (9), 18021810.

(16) Boukhachem, A.; Ouni, B.; Karyaoui, M.; Madani, A.; Chtourou, R.; Amlouk, M. Structural, Opto-Thermal and Electrical Properties of ZnO: Mo Sprayed Thin Films. Mater. Sci. Semicond. Process. 2012, 15 (3), 282-292.

(17) Xiu, X.; Pang, Z.; Lv, M.; Dai, Y.; Ye, L.; Han, S. Transparent Conducting Molybdenum-Doped Zinc Oxide Films Deposited by RF Magnetron Sputtering. Appl. Surf. Sci. 2007, 253 (6), 3345-3348.

(18) Marchand, P.; Hassan, I. A.; Parkin, I. P.; Carmalt, C. J. Aerosol-Assisted Delivery of Precursors for Chemical Vapour Deposition: Expanding the Scope of CVD for Materials Fabrication. Dalton Trans. 2013, 42 (26), 9406-9422.

(19) Dixon, S. C.; Sathasivam, S.; Williamson, B. A. D.; Scanlon, D. O.; Carmalt, C. J.; Parkin, I. P. Transparent Conducting N-Type $\mathrm{ZnO}$ :Sc-Synthesis, Optoelectronic Properties and Theoretical Insight. J. Mater. Chem. C 2017, 5 (30), 7585-7597.

(20) Potter, D. B.; Powell, M. J.; Darr, J. A.; Parkin, I. P.; Carmalt, C. J. Transparent Conducting Oxide Thin Films of Si-Doped $\mathrm{ZnO}$ Prepared by Aerosol Assisted CVD. RSC Adv. 2017, 7 (18), 1080610814.

(21) Knapp, C. E.; Carmalt, C. J. Solution Based CVD of Main Group Materials. Chem. Soc. Rev. 2016, 45 (4), 1036-1064.

(22) Li, S.; Page, K.; Sathasivam, S.; Heale, F.; He, G.; Lu, Y.; Lai, Y.; Chen, G.; Carmalt, C. J.; Parkin, I. P. Efficiently Texturing Hierarchical Superhydrophobic Fluoride-Free Translucent Films by 
AACVD with Excellent Durability and Self-Cleaning Ability. J. Mater. Chem. A 2018, 6 (36), 17633-17641.

(23) Singh, K. K.; Visser, R. J.; Rao, S.; Kumar, B.; Carmalt, C. J.; Arnepalli, R. R.; Nalamasu, O.; Saraf, G.; Sathasivam, S.; Blackman, C. S. High Efficiency Thin Film Transistor Device with Gallium Arsenide Layer. Google Patents, September 30, 2014.

(24) Zhuang, A.; Liao, R.; Lu, Y.; Dixon, S. C.; Jiamprasertboon, A.; Chen, F.; Sathasivam, S.; Parkin, I. P.; Carmalt, C. J. Transforming a Simple Commercial Glue into Highly Robust Superhydrophobic Surfaces via Aerosol-Assisted Chemical Vapor Deposition. ACS Appl. Mater. Interfaces 2017, 9 (48), 42327-42335.

(25) Zhuang, A.; Liao, R.; Dixon, S. C.; Lu, Y.; Sathasivam, S.; Parkin, I. P.; Carmalt, C. J. Transparent Superhydrophobic PTFE Films via One-Step Aerosol Assisted Chemical Vapor Deposition. RSC Adv. 2017, 7 (47), 29275-29283.

(26) Bhachu, D. S.; Sankar, G.; Parkin, I. P. Aerosol Assisted Chemical Vapor Deposition of Transparent Conductive Zinc Oxide Films. Chem. Mater. 2012, 24 (24), 4704-4710.

(27) Mittal, K. L. Adhesion Measurement of Thin Films. Electrocomponent Sci. Technol. 1976, 3 (1), 21-42.

(28) Abrahams, S. C.; Bernstein, J. L. Remeasurement of the Structure of Hexagonal ZnO. Acta Crystallogr., Sect. B: Struct. Crystallogr. Cryst. Chem. 1969, 25 (7), 1233-1236.

(29) Qazi, S. J. S.; Rennie, A. R.; Cockcroft, J. K.; Vickers, M. Use of Wide-Angle X-Ray Diffraction to Measure Shape and Size of Dispersed Colloidal Particles. J. Colloid Interface Sci. 2009, 338 (1), 105-110.

(30) Ghosh, R.; Basak, D.; Fujihara, S. Effect of Substrate-Induced Strain on the Structural, Electrical, and Optical Properties of Polycrystalline ZnO Thin Films. J. Appl. Phys. 2004, 96 (5), 26892692.

(31) Shan, F. K.; Kim, B. I.; Liu, G. X.; Liu, Z. F.; Sohn, J. Y.; Lee, W. J.; Shin, B. C.; Yu, Y. S. Blue-shift of near Band Edge Emission in Mg Doped ZnO Thin Films and Aging. J. Appl. Phys. 2004, 95 (9), 4772-4776.

(32) Nunes, P.; Fortunato, E.; Tonello, P.; Braz Fernandes, F.; Vilarinho, P.; Martins, R. Effect of Different Dopant Elements on the Properties of $\mathrm{ZnO}$ Thin Films. Vacuum 2002, 64 (3-4), 281-285.

(33) Zhang, H.; Yang, S.; Liu, H.; Yuan, C. Preparation and Characterization of Transparent Conducting $\mathrm{ZnO}: \mathrm{W}$ Films by DC Magnetron Sputtering. J. Semicond. 2011, 32 (4), 043002.

(34) Nishino, J.; Ohshio, S.; Kamata, K. Preparation of AluminumDoped Zinc Oxide Films. J. Am. Ceram. Soc. 1992, 75 (12), 34693472.

(35) Chopra, K. L.; Major, S.; Pandya, D. K. Transparent Conductors-A Status Review. Thin Solid Films 1983, 102 (1), 1-46.

(36) Hung-Chun Lai, H.; Basheer, T.; Kuznetsov, V. L.; Egdell, R. G.; Jacobs, R. M. J.; Pepper, M.; Edwards, P. P. Dopant-Induced Bandgap Shift in Al-Doped $\mathrm{ZnO}$ Thin Films Prepared by Spray Pyrolysis. J. Appl. Phys. 2012, 112 (8), 083708.

(37) Choi, J.-G.; Thompson, L. T. XPS Study of As-Prepared and Reduced Molybdenum Oxides. Appl. Surf. Sci. 1996, 93 (2), 143149.

(38) Bhachu, D. S.; Scanlon, D. O.; Sankar, G.; Veal, T. D.; Egdell, R. G.; Cibin, G.; Dent, A. J.; Knapp, C. E.; Carmalt, C. J.; Parkin, I. P. Origin of High Mobility in Molybdenum-Doped Indium Oxide. Chem. Mater. 2015, 27 (8), 2788-2796.

(39) Sabine, T. M.; Hogg, S. The Wurtzite Z Parameter for Beryllium Oxide and Zinc Oxide. Acta Crystallogr., Sect. B: Struct. Crystallogr. Cryst. Chem. 1969, 25 (11), 2254-2256.

(40) Look, D. C.; Leedy, K. D.; Vines, L.; Svensson, B. G.; Zubiaga, A.; Tuomisto, F.; Doutt, D. R.; Brillson, L. J. Self-Compensation in Semiconductors: The Zn Vacancy in Ga-Doped ZnO. Phys. Rev. B: Condens. Matter Mater. Phys. 2011, 84 (11), 115202.

(41) Soumahoro, I.; Colis, S.; Schmerber, G.; Leuvrey, C.; Barre, S.; Ulhaq-Bouillet, C.; Muller, D.; Abd-lefdil, M.; Hassanain, N.; Petersen, J.; Berrada, A.; Slaoui, A.; Dinia, A. Structural, Optical, Spectroscopic and Electrical Properties of Mo-Doped $\mathrm{ZnO}$ Thin
Films Grown by Radio Frequency Magnetron Sputtering. Thin Solid Films 2014, 566, 61-69.

(42) Potter, D. B.; Bhachu, D. S.; Powell, M. J.; Darr, J. A.; Parkin, I. P.; Carmalt, C. J. Al-, Ga-, and In-doped $\mathrm{ZnO}$ Thin Films via Aerosol Assisted CVD for Use as Transparent Conducting Oxides. Phys. Status Solidi A 2016, 213 (5), 1346-1352. 